\title{
Practical teaching can enhance teaching based on work-study combination and find university public trust
}

\author{
Lingshan Jia \\ Information Engineering Department, Environmental Management College of China, \\ Qinhuangdao, 066004, PR China. \\ 63786960@qq.com
}

Keywords: Practice Teaching; Vocational Education In College; university public trust

\begin{abstract}
For a long time, the practice teaching is the weakness of university education, and it also caused a growing crisis of confidence in university public trust. Our continuous exploration and practice to "school-enterprise cooperation and work-study combination" teaching practice show that a practical teaching based on work-study combination has an irreplaceable role to the modern university education, especially to university occupation education, and it can regain university public trust.
\end{abstract}

\section{Introduction}

Along with development of economic, we have to say that the economic development is also a "double-edged sword" to the whole education and its future developing trend, which results in the current education, especially higher expectations of university education, in a difficult and survival crossroad. Based on this problem, our medium and long term program for the development of education has sounded an alarm bell for educators [1]-[2].

\section{Trouble in university graduates}

University education is directly facing the society, people are actively pouring money into university education, urgently expect benefit from university. This requires our university education and all social sectors can have a good interface and bonding point. University and society should be integral and Synchronous development. But, in china, because of the need of reform and opening-up, more and more enterprises are turned into private or individual enterprises, more large enterprises scattered into small businesses, which forms an increasingly prominent Island between university education and social enterprise development, so they can't be synchronous development. At the same time, there are two outstanding key words in the economic development: "benefit" and "IT". University education seems to capture a combination of "IT", but this "IT" is almost completely lost the support from enterprise practice. New school university graduates' impetuous and low ability is made from the simple "IT" without a based-practice basis[3]-[5].

\section{Study and work}

The purpose of learning is to work, better learning for more excellent work. Each work area puts forward us specific requirements in knowledge, technique, and ability structure. University teachers' work is more special, the teachers' specific work is how to help their students to find a good job in her / his work field, and to have a good ability to her /his work.

In the period of IT, the concept of speed and impetuous ambivalence are entered into our heart: fast graduation, fast money and a lot of money, but I have nothing to do now, what can we do? Any student knows, the employer recruitment conditions are clearly written with work experience for several years.

The employ standard in IT times is not diploma, but the gold in diploma, also is a quality of true skill and genuine knowledge. This quality contains a lot of content: (1) "genuine knowledge " is the prerequisite of " true skill", and " true skill" is the fruit of " genuine knowledge ". (2)Genuine 
knowledge, include not only a solid basic knowledge of science, but a very good application to these basic knowledge. These " genuine knowledge ", not only be from books, but also from seriously practice. It not only knows "what", but also really knows "why" by combination of hand and head in practice. " Genuine knowledge " is a real knowledge, also is an accurate application of knowledge, which is called skill. (3)True skill, is kind of technical means and methods which can skillfully accomplish a specific task goal with the help of tools. It is an intuitive reflection of the used knowledge and technology in the process of practice. So " true skill " is the key ability, and "key ability" is the embodied technical means and methods with innovation consciousness and prominent effect within the same scope and field.

We must make students grow and mold according to the social expectations of quality and ability and the statistical standards through laboratory and practice base with exhibiting typical entities and personality. So you can improve teaching efforts based on work-study combination and find students' public trust.

\section{Benign development of teaching activities with combination of work and study}

As teachers serving in the electronic measurement technology and instrument section, we and our students often made services for enterprises by participating in the relevant project' designing, debugging, troubleshooting, etc., which all from enterprise and society in spare time, which actively combine teaching with research and production, and at the same time, students got actual combat in exercise activity, the teacher individuals made their teaching and practice mutually beneficial and complementary, skill and style of our students were adequately demonstrated.

Our claim is to teach the students knowledge, exercise their skills, accumulate and affect students' occupation quality through practical activity based on work-study combination, so that enable students to achieve the purposes which independently or freely selected their employments.

\section{Make excellent students through the combination of work and study}

The building of excellent courses is important in the occupational teaching field of university students. However, for the regression university public trust real and for the formation of their practice ability as well as occupation ability, we believe it is more important to cultivate the students with excellent quality. The facts have proven that excellent course also had many disadvantages over forming the ability of students: building excellent courses tends to occupy the teaching resources and the teaching environment with a lot of wasted effort, and the role to the formation and training of the occupation ability of students is not obvious. Our team advocated that the teachers and their students participate together in practical activities based on "work-study combination" and "production-study-research combination", which can drive and lead the students to learn to do practice, and finally excellent students with both a strong practical ability and outstanding service to social enterprises were brought out. Brand students as live advertisement in the employment, can better promote the professional development and to further improve university students' public trust.

\section{Conclusions}

The teaching practice based on school-enterprise cooperation and work-study combination contributes to the formation of the double-professional team, can construct student echelons with different ability levels, and can create brand students, which plays an irreplaceable role to the modern university education, especially to the university occupation education and can retrieve the university public trust.

\section{References}

[1] http://www.princeton.edu/main/news/archive/S16/18/96S21/. 
[2] Anderson Christopher J. \& Guillory Christine A., Political Institutions and Satisfaction with Democracy: A Cross-national Analysis of Consensus and Majoritatian Systems[J]. American Political Science Review, 1997(91), 66-81,.

[3] Beetham, David, Parliament and Democracy in the Twenty-first Century: a Guide to Good Practice, to be published by the IPU in the course of 2006.

[4] Warren H. Fox and Sarah L. Earl-Novell, Public Trust in Higher Education and A Media Review of Press Articles in California, 5-12, 2004.

[5] Cook, Timothy E. \& Gronke, Paul, Trust, Distrust, Confidence, Lack of Confidence: New Evidence of Public Opinion towards Government and Institutions from 2002, Paper prepared for delivery at the annual meeting of the Southern Political Science Association, Savannah, Georgia, November 2002. 